Nataša Visočnik Gerželi

\title{
Pahljače kot zbirateljski predmeti v vzhodnoazijskih zbirkah v Sloveniji
}

\section{Uvod}

Pahljače so prisotne $\mathrm{v}$ mnogih kulturnih okoljih in $\mathrm{z}$ raziskovanjem njihove dolge zgodovine je jasno, da so zaradi svoje raznolike uporabnosti v določenih družbah pridobile pomembno vlogo v mnogih vidikih življenja ljudi. Pahljača tako ni le predmet, ki bi nas zanimal zaradi svoje prvotne naloge hlajenja v vročih dneh, ampak zaradi uporabnosti na številnih področjih, na primer v oblačilni kulturi, uporablja se kot komunikacijski pripomoček z napisanimi pesmimi in pismi, kot reklamni pano, pri verskih ritualih in drugih obredih, kot je npr. čajni obred na Japonskem ali na Kitajskem, uporabljale so se tudi kot pripomočki v gledaliških igrah in plesih idr. V dolgi štiri tisočletni zgodovini so pahljače dobile tudi estetsko vrednost zaradi najrazličnejših poslikav, načinov izdelave in uporabe različnih materialov.

Pahljače tako kot številni drugi zbirateljski predmeti predstavljajo posamezne kulture in »odražajo družbene, idejne in ekonomske vrednote globalnega trga in družbenopolitične interpretacije posamezne družbe kot tudi posameznika« (Vampelj Suhadolnik, 2019, 95). Enako tudi Armstrongova $(1974,9)$ pravi, da pahljače niso samo nepomemben praktični ali modni privesek, ampak so tudi »manifestacija kultur in okusov«, ki pa se lahko precej prepletajo, kot je to v primeru japonskih in kitajskih pahljač, namenjenih za evropski trg, ki so se mu prilagodile. Tako nas v prvi vrsti zanima, kako so azijske pahljače postale eden izmed bolj iskanih predmetov v svetu trgovanja, izmenjav in zbiranja med posamezniki vseh družbenih slojev. Kasneje nastanejo velike zasebne zbirke pahljač, izmed katerih nekatere končajo v muzejskih zbirkah in v zbirkah drugih uradnih institucij po svetu.

$\mathrm{V}$ prispevku tako ugotavljamo, kakšno vlogo imajo pahljače, predvsem vzhodnoazijske, v muzejskih in zasebnih zbirkah. V prvem delu, ki je bolj splošen, v pregledu literature o pahljačah preučujemo, kako se je spreminjal odnos do pahljač kot zbirateljskega predmeta vse od amaterskega do strokovnega zbiranja in raziskovanja pahljač. $\mathrm{V}$ drugem delu se osredotočimo na azijske pahljače in njihovo vlogo v evropski zbirateljski kulturi. V tretjem delu pa analiziramo pahljače v treh slovenskih zbirkah vzhodnoazijskih kultur, katerih spoznavanje nam približa

DOI:10.4312/ars.14.2.73-86 
vzhodnoazijski način življenja in mišljenja, hkrati pa ovrednotimo njihovo prisotnost v slovenskih zbirkah.

\section{Zbiranje in raziskovanje pahljač}

Pahljače imajo dolgo zgodovino, najprej kot predmet, ki odganja mrčes in hladi, nato pa kot vedno bolj dodelan predmet, ki so ga uporabljali pri slovesnostih in religioznih obredih (Egipt, Grčija, Rim, Kitajska). Kasneje je imela pahljača pomembno vlogo tudi v krščanskih cerkvah (flabellum), ${ }^{1}$ pri kitajskih in japonskih slovesnostih in religijskih obredih, uporaba pa se je širila tudi na dvore, tako v Evropi kot tudi v Aziji, kjer je postala nepogrešljiv predmet vsakdanje garderobe. Z začetki raziskovanja v 15. stoletju in širitvijo trgovine na Daljni vzhod so v Evropo prispele tudi azijske (najprej predvsem kitajske) pahljače, ki so postale luksuzen predmet, ki so ga uporabljali predvsem na dvorih in med pripadniki najvišjih plasti družbe. V zgodnjem 17. stoletju so postale pomembno trgovsko blago; ko so se zanje začele zanimati tudi žene trgovcev in širša aristokracija, se je njihova uporaba razširila tudi na področje oblačilne kulture in postale so pomemben modni dodatek tako žensk kot tudi moških (Armstrong, 1974, 13-20). Nova vloga pahljač kot pomembnega modnega dodatka je nadalje pospešila izdelovanje bogato okrašenih pahljač domače proizvodnje, ki so se razširile tudi na evropske dvore in naprej med bogatejše sloje (p. t., 20-24).

$\mathrm{V}$ času širjenja uporabe na dvore, med aristokracijo in meščanstvo, ko so postale del oblačilne kulture za potrebe modnega izražanja vse od 15. stoletja naprej, pa so pahljače postajale tudi eden izmed zbirateljskih predmetov. Tako so nastajale zasebne zbirke pahljač, ki so tvorile domače modne kreacije in oblačilno kulturo, kasneje pa so pridobile širši pomen v zbirateljstvu ne samo zaradi praktične, temveč tudi estetske in simbolne vloge, pri čemer so na zbiranje vplivali osebni interesi. Kot pravi Yasaitis (2006), ljudi pritegnejo predmeti, ker so jim v določenem trenutku všeč iz različnih razlogov.

Pahljače so iz zasebnih zbirk, kjer so se ohranile zaradi estetskosti in umetniške vrednosti, v širšo javnost stopile šele leta 1870, ko je muzej South Kensington v Združenem kraljestvu postavil prvo mednarodno razstavo pod pokroviteljstvom kraljice Viktorije. S tem se je zanimanje in navdušenje za pahljače razširilo še na njihovo preučevanje kot zbirateljskega predmeta. Najprej je lady Charlotte Schreiber ${ }^{2}$ leta 1888

1 Flabellum je bila okrogla pahljača, ki so jo uporabljali v zgodnjih krščanskih cerkvah, kjer so diakoni na vsaki strani oltarja mahali z njimi, da bi pregnali mrčes od kelihov in hostije. Narejene so bile iz kovine, usnja ali pavjih peres. Podobno pahljačo najdemo kasneje tudi v grški ortodoksni cerkvi (ripidion). Vse do 6. stoletja so se pojavljale tudi kot pahljače zastave, ki so imeli samo simbolno vlogo, ni pa podatkov o širši rabi (Finnegan, 2015, 7).

2 Lady Charlotte Elizabeth Guest (kasneje Schreiber, 1812-1895) je bila ena izmed najpomembnejših zbiralk v 19. stoletju, prevajalka in podjetnica in je poleg drugih predmetov zbirala tudi pahljače. Leta 1888 in 1889 je izdala dve knjigi z zbranimi ilustracijami pahljač s komentarji (John, 2001; The Fan Circle International, 2020). 
izdala knjigo Fans and fan leaves, kjer je zbrala ilustracije pahljač in jih tudi komentirala (Ginsburg v Dorrington-Ward, 1978, 1). Leta 1895 je M. A. Flory v svoji knjigi A book about fans zapisal, da so pahljače kljub bogatemu ozadju le elegantni predmeti in muha enodnevnica, ki naj bi jih "preučevali le tisti, ki imajo dovolj prostega časa" (Armstrong, 1974, 9), se pravi le bogatejši sloj. Zatem je vse od konca 19. stoletja do nekje okoli leta 1920 izšlo še nekaj knjig, kasneje pa se je zanimanje za pahljače nekoliko poleglo.

Te prve knjige o pahljačah so sicer zelo zanimive za branje, vendar je bilo znanje o pahljačah takrat še zelo omejeno na opisovanje, vsebujejo pa tudi nekaj napačnih informacij (glej The Fan Circle International, 2020). Šele kasneje se je zanimanje za pahljače ponovno obudilo, in sicer v 70. letih 20. stoletja, ko so najprej leta $1967 \mathrm{v}$ Victoria and Albert Museum razstavili bogato zasebno zbirko orientalskih in evropskih pahljač zbiralca Leonarda Messla ${ }^{3}$ (Ginsburg v Dorrington-Ward, 1978, 1). Med velike zbiralke pahljač uvrščamo tudi Esther Oldham (1900-1984) iz Bostona v ZDA, ki je zbrala več kot tisoč pahljač, tudi iz različnih kultur, med njimi tudi nekaj t. i. etničnih pahljač, kamor je sama uvrstila pahljače iz Samoe, Indonezije in Afrike. Pahljače so jo zanimale tudi akademsko, objavila je kar nekaj člankov v raznih revijah, nazadnje pa jih je podarila različnim muzejem v ZDA (več kot 400 pahljač je dobil Museum of fine arts v Bostonu) (Gray Bennet, 1988, 10-11).

Prelomno pa je bilo leto 1974, ko je Nancy Armstrong izdala knjigo A collector's history of fans, ki predstavlja prvi primer celostnega pristopa k raziskovanju pahljač. Knjiga vsebuje oris zgodovine pahljač in njihovo kategorizacijo, in sicer predstavi poslikane pahljače (opredeljene še glede na izvor iz več evropskih dežel), tiskane pahljače (samo angleške in francoske), orientalske pahljače ${ }^{4}$ (prav tako razdeljene na poslikane in natisnjene) ter na pahljače iz perja, tekstila in zložljive pahljače brisé (Armstrong, 1974).

To je vzpodbudilo številne posameznike, da so poiskali svoje že pozabljene primerke pahljač in jih postavili na vidnejše mesto doma ali pa so jih podarili muzejem. Splošen interes med zbiratelji je vzpodbudil tudi muzeje, da so še bolj intenzivno pripravljali razstave, najprej v Veliki Britaniji in po Evropi, nato pa še $\mathrm{v}$ ZDA in drugod po svetu. Muzejske razstave pa so nudile material za raziskovanje številnim raziskovalcem, ki so jih pahljače začele zanimati holistično, poleg izvora in leta nastanka so preiskovali tudi proizvajalce, obrtnike in slikarje, načine izdelave, materiale, največkrat pa tudi vzorce, trgovske poti, skozi zgodovino razvoja pahljač pa poskušajo razumeti njihovo družbeno vlogo. Tukaj lahko izpostavimo preplet akademske in zbirateljske

3 Polkovnik Leonard C. R. Messel (1872-1953) je bil navdušen vrtnar in poznavalec umetnosti in od leta 1905 naprej ljubitelj pahljač. Po njegovi smrti je njegova hčerka Anna, grofica Rosse (1902-92), muzeju Fitzwilliam podarila okrog sto najrazličnejših pahljač (The Fitzwilliam museum, 2020).

4 Armstrongova (1974, 12-14) med orientalske pahljače uvršča kitajske in japonske pahljače, kjer obravnava poslikane pahljače iz Kitajske in Japonske, medtem ko tiskane pahljače predvsem iz Japonske. 
stroke, ko sprva zasebni zbiratelji z lastnimi študijami spodbudijo razvoj poznavalstva $s$ tega področja, hkrati pa je viden še obraten vpliv, ko akademske študije pospešijo zbirateljstvo.

Jasno je tudi, da se je že v času, ko je raziskovala Nancy Armstrong (1974, 9), odnos do pahljač, do njihovega zbiranja in do raziskovanja zelo spremenil. Zdaj so imeli na voljo več različnih informacij, podatki so postali dosegljivi vse do 17. stol. pr. n. št., kar je razširilo zanimanje za pahljače, ki so ga imeli konec 19. stol., ko so zviška gledali na vse, kar je bilo narejeno pred letom 1800. Zbirateljsko zanimanje se je razširilo tudi na različne vrste umetnosti, med drugim tudi na kitajsko in japonsko slikarstvo iz 19. stoletja, ki je tudi pridobilo na vrednosti. Tako so se najrazličnejše in "nenavadne" pahljače pojavljale v etnografskih muzejih, kamor so spravljali tudi kitajske in japonske pahljače. ${ }^{5}$ Armstrongova izpostavlja, da naj bi interes za zbiranje pri prvotnih zbiralcih zbudila predvsem drugačnost azijskih pahljač, da so nanje gleda kot »na miniaturna umetniška dela iz eksotičnih materialov iz daljnih dežel, ki so videti, kot da jih je ustvarila čarovnija in ne prsti smrtnika« (1974, 9-10). Zatem izpostavi, da naj bi se zanimanje zbiralcev danes razširilo še na obliko, postopke izdelave, material, velikost itd.

Po prvih raziskavah se je pojavilo še lepo število knjig, med njimi tudi nekaj del z enakimi naslovi, kot so Fans (A collector's guide) avtorice Nancy Armstrong (1984; 1990), Fans avtorice Helene Alexander (1989) in Fans avtoric Avril Hart in Emme Taylor (1998). K zbirki knjig o pahljačah se pridružujejo še Unfolding beauty: The art of the fan Anne Gray Bennet (1988), The fan museum Hélène Alexander in Hand fans: an illustrated history Kathy Finnegan (2015). ${ }^{6}$

Številna dela v angleškem jeziku pa so nastala tudi o vzhodnoazijskih pahljačah, predvsem japonskih in kitajskih (Dorrington-Ward, 1978; The fan museum, 2001; Hutt in Alexander, 1992 in 2015; Faulkner, 2001; Iröns, 1981a in 1981b, idr.). Sicer pa ne smemo pozabiti tudi indijskih pahljač pankha, ki se poleg kitajskih in japonskih najpogosteje pojavljajo v zbirkah na zahodu, a so zelo malo raziskane (glej The fan museum, 2004).

Zbiratelji in ljubitelji pahljač so ustanovili razna društva, kot je npr. Fan Circle International, ${ }^{7}$ muzeji so postavljali razstave pahljač, ki so jih spremljali tudi katalogi z zelo bogatimi informacijami o razstavnih predmetih in s kakovostnimi fotografijami, ki danes služijo kot reference za zbiratelje in so omogočili širitev znanja o pahljačah (Armstrong, 1990, 11-12). Razstave pahljač tako še danes privabljajo številne

5 Kitajske in japonske pahljače so po prihodu v Evropo v skladu s takratnim kolonialnim diskurzom dobile ime orientalske pahljače (glej Armstrong, 1974, 121-145) in so se znašle v zgodnjih etnografskih muzejih v t. i. etnografskih zbirkah, ki tvorijo eno izmed kategorij, kamor zbiralci, akademiki in zgodovinarji danes uvrščajo predmete še iz drugih neevropskih in neameriških držav. Konec 19. stoletja se je namreč Orient premaknil precej na daljni Vzhod, da je vključeval tako islamski svet, kot Indijo in Vzhodno Azijo, med katero so uvrstili tudi Kitajsko in Japonsko (Clunas, 1994, 328).

6 Za več podatkov o literaturi o pahljačah glej spletno stran The Fan Circle International.

7 https://www.fancircleinternational.org/. 
obiskovalce, pahljače pa kot zbirateljski predmeti v zadnjih letih pridobivajo tudi na vrednosti in ceni. Nastali so najrazličnejši priročniki z napisanimi navodili, kako zbirati pahljače in kje jih kupiti (Fan Circle International, 2020), kajti trg s starinami in umetniškimi izdelki je pahljače sprejel z odprtimi rokami.

\section{Azijjke pahljače v Evropi}

Čeprav so bile poti z Vzhoda v Evropo, ki so prinašale svilo, začimbe in nekatere luksuzne predmete, odprte že prej, so pahljače v Evropo v večjih količinah prišle šele $\mathrm{v}$ 16. stoletju $\mathrm{z}$ razvojem pomorske trgovine s podjetji kot Britanska vzhodnoindijska družba (British East India Company) (1600) ali Nizozemska vzhodnoindijska družba (1602), ko so se znašle na ladjah kot spremljevalke porcelana (Grey Bennet, 1988, 13). Najprej so se na evropskih dvorih znašle ovalne pahljače, v 17. stoletju pa so del evropskega dvornega sveta postale še zložljive pahljače. Do konca 17. stoletja pa so se z njimi hladile in se krasile tudi žene trgovcev in aristokracije (Alexander, 2015, 4-5).

Od 17. do sredine 19. stoletja so na azijskem trgu za evropske potrošnike najprej prevladovale predvsem kitajske pahljače, po odprtju Japonske, od leta 1868 naprej, pa tudi japonske pahljače. Prvi primerki pahljač so bili, kot pravi Iröns (1981b, 4), "po orientalskih« standardih večinoma precej slabe kakovosti, saj so bili narejeni za manj kritičen evropski trg, vendar sta prefinjenost in spretnost izdelave pahljač pritegnili zanimanje Evropejcev, ki so jih začeli vneto kupovati. Takrat je imel na Kitajskem velik vpliv na oblikovanje pahljač slog iz 16. stoletja, in sicer chinoiserie kot mešanica različnih orientalskih slogov s slogi rokokoja, baroka, gotike in drugimi evropskimi slogi, ki so se jim zdeli primerni. Ta slog dekoracije je dosegel vrh v 18. stoletju (Hart in Taylor, 1998, 39). Odslikaval je evropske predstave o Kitajski in se je razširil med evropskim plemstvom (najdemo ga tudi v dvorcih na Slovenskem) v 17. in 18. stoletju (Čeplak Mencin, 2012, 14).

Japonska pa je med 17. in sredino 19. stoletja imela le malo stika s tujino, trgovina je bila dovoljena le za nizozemske in kitajske trgovce in je potekala na umetnem otoku Deshima, ki je bil povezan z Nagasakijem. Vse to se je spremenilo s prihodom ameriških ladij leta 1853 in posledičnim sporazumom o prijateljstvu in trgovanju med Japonsko in ZDA, kar je odprlo japonska pristanišča najprej za ameriške trgovce (Kashima, 1993). Tujci in vplivi iz tujine so postopoma prodirali na Japonsko ob koncu obdobja Edo (1600-1868) in v začetku obdobja Meiji (1868-1912), hkrati pa se je tudi na Zahodu izredno povečalo zanimanje za Japonsko. To se je navezalo predvsem na umetnine, ${ }^{8}$ kot so med drugim japonske grafike. Japonski obrtniki so se temu prilagodili. Posledično so nastale umetnine, ki jih je imel Zahod za popolnoma

8 Eden izmed pomembnih raziskovalcev japonske in tudi kitajske umetnosti je bil Ernest F. Fennolosa (1853-1908), ki je nad novostmi navdušene Kitajce in Japonce ozaveščal o pomembnosti njihove tradicionalne kulture (Fennolosa, 2007). 
japonske, Japonci sami pa so jih komaj prepoznali kot take (Hutt in Alexander, 1992, 28). Tako se je na Japonskem pod vplivom evropskega sloga japonizma9 začela manufaktura pahljač izključno za izvoz. Sprva so bile namenjene aristokratskim posameznikom, kmalu pa so postale priljubljene tudi v širših krogih predvsem po predstavitvah na prvih svetovnih razstavah proti koncu 19. stoletja, ko so na višku popularnosti japonske pahljače izvažali v ogromnih količinah, predvsem v ZDA, Francijo, Anglijo in Nemčijo (p. t., 29). Tako je pahljača, poleg številnih drugih predmetov, postala del nepogrešljive umetniške dediščine Kitajske in Japonske, ki je bila v Evropi zelo cenjena (Iröns, 1981a, 46).

\section{Azijske pahliače v slovenskih muzejih}

V Sloveniji je v muzejih in drugih javnih inštitucijah 21 različnih vzhodnoazijskih zbirk oziroma zapuščin posameznikov, med katerimi niso vse evidentirane samostojno v skladu z muzejsko stroko (Vampelj Suhadolnik, 2019, 97-100). Te predmete so večinoma konec 19. stoletja in v prvi polovici 20. stoletja na slovenska tla iz Vzhodne Azije prinesli ali poslali pomorščaki, misijonarji, diplomati, znanstveni sodelavci in popotniki. Med temi predmeti najdemo tudi pahljače iz Vzhodne Azije, med katerimi prevladujejo japonske in kitajske. Med zbirkami, kjer se nahaja večje število pahljač, izstopajo predvsem tri: Zbirka Alme Karlin, Zbirka predmetov iz Azije in Južne Amerike, ki ju hrani Pokrajinski muzej Celje, in Skuškova zbirka iz Slovenskega etnografskega muzeja v Ljubljani, ki jih prispevek tudi podrobneje predstavi. Čeprav najdemo v Zbirki Alme Karlin in Zbirki predmetov iz Azije in Južne Amerike tudi pahljače iz drugih držav (Indija, Tajska, Indonezija idr.), se osredotočamo samo na kitajske, japonske in korejske pahljače. Do zdaj je najbolj raziskana Zbirka Alme Karlin, iz katere so bile japonske, kitajske in korejske pahljače del razstave Azija me je uročila v Pokrajinskem muzeju Celje v letu 2019.

Pri nekaterih pahljačah je provenienco zelo težko zagotovo ugotoviti, saj ni nobene informacije o lastniku, nakupu, letu izdelave, a o izvoru lahko sklepamo glede na obliko, način izdelave, poslikave ali stil. Največ pahljač z manjkajočimi podatki je zaradi njene specifične narave ravno v Zbirki predmetov iz Azije in Južne Amerike. ${ }^{10}$

9 Japonizem se je v Evropi začel po velikem navdušenju nad vsem japonskim, potem ko je Japonska sodelovala na mednarodnih razstavah med letoma 1873 in 1901. Takrat so imeli Evropejci prvič na vpogled japonske izdelke in umetnost, kar je še zlasti močno vplivalo na francosko umetnost. Novemu zanimanju in zahtevam po bolj dovršenih in okrašenih pahljačah, ki so izražale tudi njihove sposobnosti, so se prilagodili tudi japonski obrtniki. Bambus so zamenjali z lesom, slonovino in želvovino, ki so jih okrasili z zlatim lakom (Finnegan, 2015, 78).

10 Predmeti iz Zbirke predmetov iz Azije in Južne Amerike večinoma prihajajo iz Federalnega zbirnega centra. Federalni zbirni centri so bili v na novo nastalih jugoslovanskih republikah organizirani poleti 1945. Njihovo delovanje in organizacija je bila predpisana z Navodili za ustanavljanje in poslovanje zbirnih centrov, ki jih je izdalo Ministrstvo za prosveto DFJ 31. julija 1945. Predmeti so bili ob konfiskaciji le skopo popisani, kar otežuje iskanje provenience (Kodrič-Dačič, 2000). 
Tabela 1: Število in izvor pahljač iz treh zbirk

\begin{tabular}{llll}
\hline Zbirka/Izvor & Kitajska & Japonska & Koreja \\
\hline Skuškova zbirka & 8 & 2 & $\mathrm{x}$ \\
\hline Zbirka Alme Karlin & $2 ?$ & 12 & 2 \\
\hline $\begin{array}{l}\text { Zbirki predmetov iz Azije in } \\
\text { Južne Amerike }\end{array}$ & 26 & 1 & $\mathrm{x}$ \\
\hline
\end{tabular}

Pri analizi pahljač moramo biti poleg kraja in časa nastanka pozorni še na nekaj drugih kriterijev, to so oblika, material, motivi, barve, način izdelave, namen uporabe idr. $\mathrm{V}$ osnovi se glede na obliko pahljače delijo na tri tipe: nezložljiva/fiksna ali ovalna pahljača, pahljača brisé (iz povezanih letvic) in zložljiva pahljača. Z različnimi kombinacijami zgoraj naštetih elementov pa ti tipi tvorijo še druge različne tipe pahljač z različnimi slogi, kot so izvezene ovalne pahljače, pahljače s svileno tapiserijo, izvezene in poslikane, slonokoščene brisé, lesene izrezljane brisé, pahljače kokarde, bambusove pahljače s poslikanim papirjem ali blagom - zložljive in ovalne, tiskane pahljače idr. (glej Armstrong 1974; Armstrong 1990; idr.). Nekatere od teh tipov pahljač najdemo tudi v naših zbirkah, ki jih v nadaljevanju tudi predstavimo.

V Zbirki Alme Karlin (1889-1850), popotnice iz slovenskih krajev, ki se je med svojim potovanjem okrog sveta med letoma 1919 in 1927 ustavila tudi v Aziji, je kar 25 pahljač, kar izraža tudi njeno navdušenost nad njimi. Pahljače so zelo raznovrstne tako po provenienci, obliki, motivih kot po načinih izdelave, izvirajo pa iz obdobja od konca 19. stoletja do začetka 20. stoletja.

Japonskih pahljač je kar dvanajst, od tega je deset ovalnih in dve sta brisé. Ovalne pahljače ali uchiwa 団扇 nadalje lahko kategoriziramo v poslikane in tiskane pahljače. Tri poslikane pahljače so narejene na podoben način, vendar so avtorji oziroma delavnice različne in neznane. Papir je utrjen in pobarvan na rdeče s kakijevim sokom, nato pa so s črnilom narisani motivi rož (slive, češnje in potonika) in ptic (jap. kacho-e 花鳥 絵), ki simbolizirajo moralne vrline, prinašajo pa veselje, srečo in mir, izražajo pa tudi povezanost $\mathrm{z}$ naravo in štirimi letnimi časi. ${ }^{11}$

Drugi sklop ovalnih pahljač sestavljajo tiskane pahljače, kjer so natisnjeno sliko nalepili na ogrodje pahljače in jo nato obrezali, kar so lahko večkrat ponovili, vse dokler je bil okvir cel. Zbirko Alme Karlin sestavljajo pahljače z motivi iz dveh skupin, eno so motivi že prej omenjenih cvetlic in ptic, drug pogost motiv pa so podobe kurtizan ali lepih žensk, ki jih uvrščamo v kategorijo t. i. slik lepotic (jap. bijin-ga 美人画). Pogosto so tiskali tudi reprodukcije slavnih slikarjev, kot je na primer Hiroshige z lesorezov ukiyo-e 浮世絵 (glej Faulkner, 2001; Kyōto sensu uchiwa, 2019). Ta kategorija

11 Pogosta tema v japonski umetnosti je tudi prepletanje letnih časov, ki jo prav tako najdemo na nekaterih pahljačah v Zbirki Alme Karlin. Za funkcionalne predmete, kot je pahljača, je veljalo, da se obdobje prodaje lahko podaljša, saj se pahljača lahko uporablja tako poleti kot jeseni. 
tiskov na pahljačah iz 18. in 19. stoletja je še zelo slabo raziskana, zaradi večkratne uporabe pahljač pa se jih je ohranilo le malo (glej tudi Thomsen 2019), kar umešča te pahljače med posebej pomembne predmete (slika 1).

Preostali dve japonski pahljači sta zložljivi pahljači (jap. ōgi 扇 ali sensu 扇子), ki sta izdelani v najstarejši tehniki - z letvicami iz lesa ali slonovine, povezanimi s trakom, zato spadata v sklop pahljač brisé. Letvice so $\mathrm{v}$ naravni barvi in niso poslikane, le svileni trak je pri pahljači iz sandalovine zelen, pri pahljači iz slonovine pa bel.

Tudi kitajski pahljači sta tipa brisé, narejene iz letvic, odlikuje pa ju gost in droben vzorec, izrezljan v sandalovino in slonovino, povezani z belim svilenim trakom. Podobne pahljače se pogosto pojavljajo tudi v Indiji, zato je včasih težko določiti provenienco.

Edini korejski pahljači buchae 부채 (slika 2) v Sloveniji sta poslikani s tribarvnim simbolom taegeukseon (kit. yin yang), ki pomeni temeljni zakon narave ali harmonijo. Motiv je naslikan na papir z rdečo, modrozeleno in rumeno barvo, za utrditev pa je bil uporabljen kakijev sok. Ročaj je črno pobarvan. Poleg tribarvnega vzorca je naslikana še potonika, ki kot kraljeva roža simbolizira kraljevino, pogum in čast, ${ }^{12}$ hkrati kot roža bogatih pomeni tudi blaginjo in plemstvo.

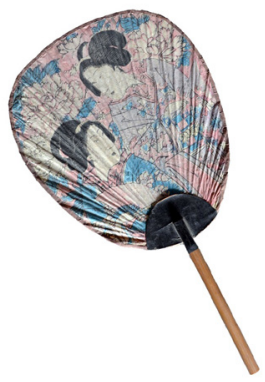

Slika 1: Ovalna pahljača uchiwa za večkratno uporabo; bambus, papir, barvni tisk, Japonska, 1880-1900, K 76, Zbirka Alme Karlin, PMC (foto: PMC).

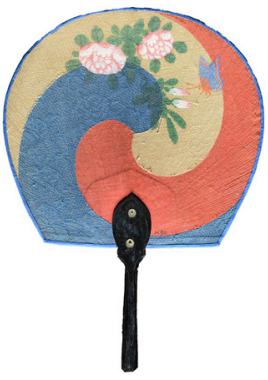

Slika 2: Ovalna pahljača buchae, tribarvna, $\mathrm{z}$ vzorcem tegukson in cvetlico, poslikan papir, okvir iz bambusa, Koreja, zač. 20. st., K 80, Zbirka Alme Karlin, PMC (foto PMC).

Pahljače Alme Karlin so večinoma dobro ohranjene, le pri ovalnih pahljačah s tiskanim motivom ponekod manjka ročaj ali pa je poškodovan papir, kar pomeni, da so bile veliko v uporabi že na Japonskem, še preden jih je dobila v roke, nekatere kot dar, nekatere pa je tudi sama uporabljala za hlajenje (Karlin, 2006, 238, 278). 
Tudi zbirka Ivana Skuška (1877-1947), mornariškega častnika, ki je med letoma 1914 in 1920 bival na Kitajskem, med drugimi tudi v Pekingu, je izredno bogata in raznolika. S premišljenimi nakupi v pekinških starinarnicah je želel po svoji vrnitvi približati daljno kitajsko kulturo svojim sonarodnjakom (Vampelj Suhadolnik, 2019, 35-36). Med številnimi predmeti je osem kitajskih in dve japonski pahljači, ki sta bili najverjetneje v lasti njegove japonske žene Tsuneko Kondō Kawase (Marija Skušek).

Med kitajskimi pahljačami so tri pahljače okrogle, pri eni od teh je rob konkavno usločen, okrašene so z izvezenimi motivi ptic (najpogosteje pava) in cvetlic ter dreves (magnolija). Izvezeno svilo obkroža lesen ali slonokoščen rob, tudi ročaji so umetelno izrezljani iz bambusa, pobarvanega v črno, ali iz slonovine z izvezenim svilenim trakom (slika 3).

Ena pahljača je ovalne oblike starega sloga, kasneje imenovanega pahljače Swatow (kit. Shantou 汕头市) (slika 4), ki so izdelane v delavnicah v 19. stoletju, čeprav ne izvirajo od tam. Njihova izdelava je precej zahtevna, okvir je narejen iz več bambusovih kosov, z vstavljeno žico in ovitih s papirjem. Le nekaj takšnih pahljač se je ohranilo, zato je njihova vrednost velika. Na njej so naslikane podobe ljudi in stavbe v ozadju v gorski pokrajini. Vse štiri pahljače uvrščamo v slog okroglih ali ovalnih pahljač, ki originalno ni bil izdelan za izvoz, ampak so pahljače v tem slogu uporabljali Kitajci sami v 18. in 19. stoletju. Kljub temu se jih je veliko znašlo tudi na Zahodu, danes spadajo med redkosti oziroma jih uvrščamo med antične umetnine, ki na umetniških dražbah lahko dosegajo visoke zneske.

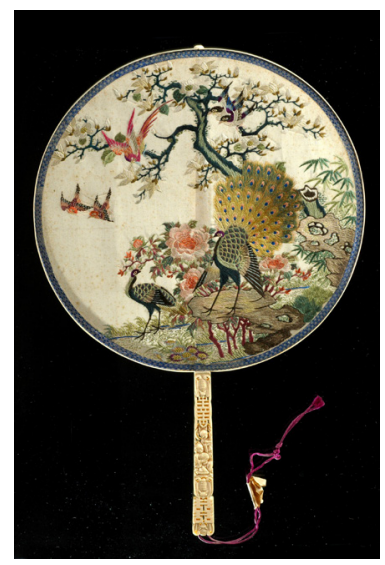

Slika 3: Okrogla pahljača; vezena svila (figura pava in pavice, cvetoča magnolija, potonika, ptiči, bambus in skale), slonokoščen, rezljan držaj, 42,3 x 27,5 cm, 19. stol., $304 \mathrm{MG}$ (150), Zbirka

Ivana Skuška, SEM (foto: SEM).

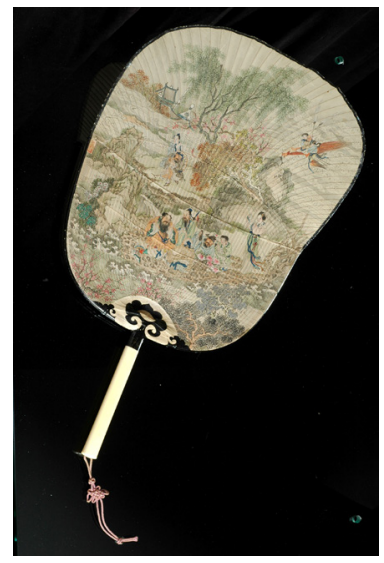

Slika 4: Ovalna pahljača, poslikan papir (taoistični modreci in gorska pokrajina, ptica žerjav), slonokoščen ročaj, $42 \mathrm{x}$ 25,5 cm, 18.-19. stol. (?), $306 \mathrm{MG}$ (152), Zbirka Ivana Skuška, SEM (foto: SEM). 
Tri kitajske pahljače so zložljive, od tega je ena pahljača brisé iz izrezljanih slonokoščenih letvic, zvezanih s svilenim trakom v beli barvi. Ta pahljača je precej poškodovana, podobno pahljačo najdemo tudi v zbirki Alme Karlin. Drugi dve zložljivi pahljači sta iz bambusovih tankih letvic, na katerih je obojestransko zalepljen poslikan papir. Na eni je motivika rože v svetlem okvirju, preostali del pa je pobarvan v črno, z napisom v kitajskih pismenkah. Na drugi pahljači je na eni strani naslikana veja $s$ cvetovi in cvetlico, nad motivom pa je tekst v kitajskih pismenkah, ki je tudi na drugi strani. Pogosto se na pahljačah poleg poslikave pojavlja tudi kaligrafski zapis.

Japonski pahljači sta sloga maiōgi 舞扇, obojestransko sta poslikani z motivi cvetja in vej. Takšne pahljače se uporabljajo za odrske umetnosti, kot so kabuki, nō ali ples nihon buyō, zato je tudi poslikan papir trdnejši in zaradi tega bolj trajen, na spodnji strani ročaja sta dve mali svinčeni uteži, ki omogočata lažje ravnanje s pahljačo na nastopih.

Tretja neevropska zbirka, v kateri se nahajajo med drugimi tudi kitajske in japonske pahljače, je Zbirka predmetov iz Azije in Južne Amerike, kjer je kar 26 kitajskih pahljač in ena japonska pahljača. Zanimiva je zbirka 22 zelo podobnih zložljivih pahljač iz istega materiala (bambusov ročaj in letvice $z$ enostranskim poslikanim papirjem) in poslikanih $\mathrm{v}$ istem slogu in $\mathrm{z}$ isto motiviko - podobe iz znanega kitajskega romana Potovanje na Zahod, ki se nadaljujejo iz ene v drugo, na petih pahljačah pa je narisan isti motiv taipinškega upora (1850-1864).

Kitajsko zbirko pahljač dopolnjujeta še dve zložljivi pahljači. Prva je poslikana na obojestranskem papirju srebrne barve $\mathrm{z}$ motivi cvetlice $\mathrm{v}$ roza in zeleni barvi. Robovi

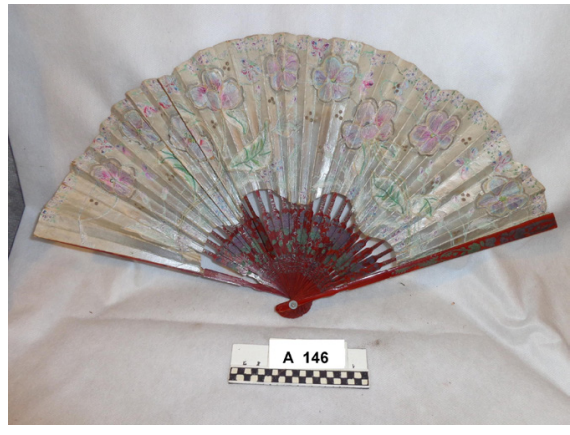

Slika 5: Zložljiva pahljača, papir, les, poslikana in izvezena motivika cvetja (v. 22,7), A 146, Zbirka predmetov iz Azije in Južne Amerike, PMC (foto: PMC).

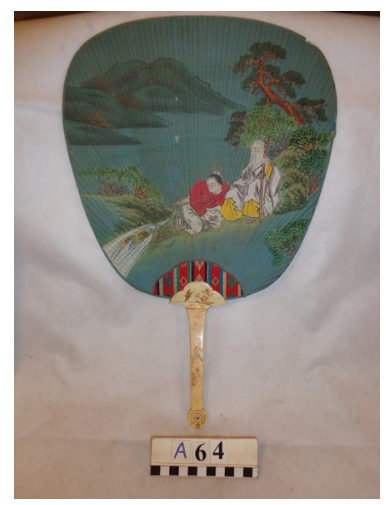

Slika 6: Ovalna pahljača, papir, slonovina, pozlata, obojestransko poslikana (1. gorska krajina, figure učitelja in učenca, 2. cvetje in ptice), (v. 45), A 64, Zbirka predmetov iz Azije in Južne Amerike, PMC (foto: PMC). 
cvetlice so izvezeni v papir (slika 5). Ogrodje oziroma letvice so lakirane z rdečim lakom in poslikane $\mathrm{z}$ istim cvetjem. Zadnja kitajska pahljača je velikega formata (̌̌. 43,2 $\mathrm{cm}$ ) in iz rdečega blaga, na obeh straneh enako poslikana s cvetjem.

Preostali dve kitajski pahljači sta ovalni in poslikani, od tega ima ena pahljača rob konkavno usločen na štirih straneh (videz pravokotnika) in je poslikana z motivoma pokrajine in figuralike. Pahljača ima leseni ročaj in je precej poškodovana. Druga ovalna pahljača (slika 6) pa je veliko bolj dragocena, je dobro ohranjena, z zlato poslikanim slonokoščenim ročajem in poslikano motiviko učitelja in učenca, sedečima ob boru in reki na eni strani ter pticami in cvetjem na drugi strani. Ozadje je v temno modri barvi.

Tudi edina japonska pahljača v zbirki je velikega formata $(\check{s} .75,5 \mathrm{~cm}$ ) in je tipa mita ōgi (velikanska pahljača), ki naj bi jo v preteklosti na Japonskem uporabljali za slovesnosti in religijske rituale in je edina tako velika japonska pahljača pri nas, redko pa jo opazimo tudi v zbirkah po svetu. Na obeh straneh je poslikana $\mathrm{z}$ motivom ptic in cvetja ter dreves, na eni strani je ozadje rdeče, na drugi pa rjavo. Ogrodje je leseno, palice so polakirane $\mathrm{v}$ temno rjavo, na zunanji palici pa je $\mathrm{z}$ zlato barvo naslikana trta in grozdje ter ptica v slogu inkrustracije shibayama.

\section{Zaključki}

Pahljače so zaradi svoje majhnosti in prenosljivosti, praktičnosti izredno hvaležen predmet za zbiranje. Poleg široke palete uporabnosti nas pri pahljači kot umetniškem predmetu privlačijo tudi dekoracija, material in izdelava. Način zbiranja pahljač in odnos do zbiranja sta se precej spremenila - vse od ljubiteljskega pogleda na predmet kot nekaj lepega in privlačnega do bolj kompleksnega zanimanja zanje s širšim in bolj celostnim pogledom tako na posamezen predmet kot tudi na zbirko. Pri tem izpostavimo preplet akademske in zbirateljske stroke, najprej zasebni zbiratelji z lastnimi študijami spodbudijo razvoj znanja s tega področja, na drugi strani pa akademske študije pospešijo zbirateljstvo.

Čeprav v slovenskih zbirkah vzhodnoazijskih pahljač ni veliko in so bile za slovenske popotnike le sestavni del zbirke predmetov, ki so jih prinesli iz tujine, pa predstavljajo pomemben košček v mozaiku zbirk, katerih preučevanje nam razkriva način življenja in mišljenja ljudi na drugem koncu sveta.

Analiza kitajskih, korejskih in japonskih pahljač v vseh treh neevropskih zbirkah nam pokaže veliko pestrost pahljač, ki prikazujejo raznolikost motivike, oblik, materialov in načina izdelave; variacije so tudi med posameznimi primeri iz iste države. Med japonskimi pahljačami prevladujejo ovalne pahljače $\mathrm{z}$ različnimi motivi, materiali in izdelavo, le malo je zložljivih. Korejski pahljači imamo le dve, ovalni s podobnim motivom. Kitajskih pahljač je največ, pestra pa je tudi njihova podoba, vse od ovalnih, 
zložljivih in brisé. Tudi način izdelave in materiali so številni, izstopajo poslikana ali izvezena motivika na svilo ali papir in pozlačeni motivi na letvicah. Hkrati pa nam podroben pogled na predstavljene pahljače pokaže, da se določeni elementi pojavljajo $\mathrm{v}$ vseh treh kulturah hkrati, na primer motivi cvetja in ptic, katerih simbolizem je tudi lahko podoben, vidimo pa tudi prenos oblik in načina izdelave (kakijev sok).

Med pahljačami je kar nekaj primerov, ki so redki tudi na svetovni ravni, tako glede na časovno umestitev zbranih pahljač iz 19. stoletja in začetka 20. stoletja kot tudi glede kakovosti in posebnosti njihove izdelave. Zaradi tega so še bolj pomembne za slovenski prostor. Med takšnimi primeri lahko izpostavimo japonske tiskane pahljače za večkratno uporabo, korejski pahljači, kitajske okrogle ali ovalne pahljače in pahljači velikega formata. Analiza pahljač v zbirkah se nadaljuje, v nastajanju so še drugi prispevki, ki s poglobljenimi raziskavami preučujejo posamezne pahljače od blizu in tako umeščajo azijske pahljače pri nas $\mathrm{v}$ slovenski in $\mathrm{z}$ vzpostavitvijo spletne baze tudi $\mathrm{v}$ svetovni zbirateljski in muzealski prostor.

\section{Zahvala}

Prispevek je nastal v okviru projekta Vzhodnoazijske zbirke $v$ Sloveniji: vpetost slovenskega prostora $v$ globalno izmenjavo predmetov in idej z Vzhodno Azijo (2018-2021) (št. J7-9429) in programske skupine Azijski jeziki in kulture (št. P6-0243), ki ju iz državnega proračuna financira Javna agencija za raziskovalno dejavnost Republike Slovenije.

\section{Viri in literatura}

Alexander, H., The Fan Museum, London 2001.

Alexander, H., Fans, Oxford (1989) 2002.

Alexander, H., Made in China, Catalogue, London 2015.

Armstrong, N., A collector's history of fans, New York 1974.

Armstrong, N., Fans. A collector's guide, London (1984) 1990.

Clunas, C., Oriental antiquities/ Far Eastern art, Positions 2 (Jesen 1994), str. 318-355.

Čeplak Mencin, R., V deželi nebesnega zmaja : 350 let stikov s Kitajsko, Ljubljana 2012.

Dorrington-Ward, C., Fans from the East, New York 1978.

Faulkner, R., Hiroshige fan prints, London 2001.

Fenollosa, E. F., Epochs of Chinese and Japanese art: An outline history of East Asiatic design, San Diego 2007 (1912).

Finnegan, K., Hand fans. An illustrated history, London 2015.

Gray Bennet, A., Unfolding beauty. The art of the fan, Boston 1988.

Hart, A. idr., Fans, London 1998.

Hutt, J. idr., Ōgi: A history of the Japanese fan, London 1992.

Iröns, N. J., Fans of Imperial Japan, Hong Kong 1981a.

Iröns, N. J., Fans of Imperial China,Hong Kong 1981b. 
John, A. V., The lives of lady Charlotte Guest, v: 150 Jahre "Mabinogion" - deutsch-walisische Kulturbeziehungen, (ur. Maier, B. in Zimmer, S.), Berlin 2001, str. 157-166, https://doi. org/10.1515/9783110951646-015.

Karlin, A. M., Samotno potovanje v daljne dežele: tragedija ženske, Celje 2006.

Kashima, M. 鹿島䒽, Heian Jidai ni okeruhiōgi ni tsuite 平安時代における檜扇について. Tsukuba Daigaku geijitsu kenkyūsh i筑波大学芸術学研究誌 10, 1993, str. 23-44, http:// hdl.handle.net/2241/00153170 [20. 11. 2020].

Kyōto sensu uchiwa shōkōkyō dōkumiai 京都扇子団扇商工協同組合, 2019, Kyōsensu Kyōuchiwa 京扇子・京うちわ (Kjotske zložljive in nezložljive pahljače), http://www.sensu-uchiwa.or.jp/ [4. 11. 2019].

Kodrič-Dačič, E., Federalni zbirni center in njegov prispevek k dopolnitvi fondov Narodne in univerzitetne knjižnice, Knjižnica 4, 2000, str. 51-63.

The Fan Circle International, 2020, https://www.fancircleinternational.org/ [15. 6. 2020].

The Fan Museum, Pankhā: Traditional crafted hand fans of the Indian subcontinent from the collection of Jatin Das, London 2004.

The Fan Museum, https://www.thefanmuseum.org.uk/ [16. 6. 2020].

The Fitzwilliam Museum, https://www.fitzmuseum.cam.ac.uk/gallery/fans/fitzcollection.html [20. 9. 2020].

Thomsen, H. B., Japanische Holzschnitte / Japanese Woodblock Prints: aus der Sammlung Ernst Grosse, Petersberg 2018.

Vampelj Suhadolnik, N., Zbirateljska kultura in vzhodnoazijske zbirke v Sloveniji, v: Procesi in odnosi v Vzhodni Aziji: Zbornik EARL, (ur. Bekeš A., idr.), Ljubljana 2019, str. 93-113.

Yasaitis, K. E., Collecting culture and the British Museum, Curator 49 (4), 2006, str. 449-462.

\section{Nataša Visočnik Gerželi}

\section{Pahljače kot zbirateljski predmeti v vzhodnoazijskih zbirkah v Sloveniji}

Ključne besede: zbirateljstvo, pahljače, vzhodnoazijske zbirke, Japonska, Koreja, Kitajska

Prispevek predstavlja in raziskuje vlogo pahljač kot zbirateljskega predmeta, pri čemer se še posebej osredotoča na vzhodnoazijske pahljače v slovenskih muzejih v okviru raziskovanja vzhodnoazijskih zbirk. Pahljačo $\mathrm{v}$ mnogih kulturah skozi dolgo zgodovino spoznamo kot predmet $\mathrm{z}$ zelo raznovrstno uporabnostjo, saj združuje praktične, obredne in estetske funkcije. Tako poleg praktične uporabnosti za hlajenje $\mathrm{v}$ vročih dneh svojo pomembno vlogo izkazuje tudi v družbenem življenju na številnih področjih. Pahljača je tudi zelo hvaležen predmet za zbiranje zaradi svoje velikosti, izdelave in poslikave, pripisujemo pa ji tudi lahko visoke estetske vrednosti. $V$ tem prispevku nas tako najprej zanima vrednotenje pahljač kot zbirateljskega predmeta, nato preučimo pot pahljač iz Azije in uvrstitev azijskih pahljač v strokovni prostor zbirateljev in akademske sfere, zaključimo pa s pregledno analizo pahljač v treh neevropskih zbirkah predmetov v slovenskih muzejih. Iz pregleda pahljač ugotovimo, da se v zbirkah nahajajo zelo raznolike pahljače iz kitajskega, japonskega in korejskega prostora, med katerimi pa je nekaj zelo redkih pahljač tudi na svetovni ravni, s čimer lahko uvrstimo zbirke med izredno pomembne v slovenskem prostoru. 


\title{
Nataša Visočnik Gerželi
}

\section{Fans as collector's items in the East Asian Collections in Slovenia}

\author{
Keywords: collecting, fans, East Asian collections, Japan, Korea, China
}

The article presents and explores the role of fans as a collector's item, focusing in particular on East Asian fans in Slovenian museums as part of a research project examining East Asian collections. In many cultures fans have long been known as objects with a wide variety of uses, as they combine practical, ritual and aesthetic functions. Thus, in addition to their practical use for cooling on hot days, fans have also had an important role in social life in many areas. Fans are also ideal objects to collect due to their small size and easy transportation, and with the high levels of workmanship and painting often seen, they can have high aesthetic value. In this paper, we are first interested in the evaluation of fans as a collector's item, then we examine the path of fans from Asia and the classification of Asian fans in the world of collectors and academia, and conclude with an analysis of fans in three non-European collections of objects in Slovenian museums. From the review of fans presented in this study, we find that the collections contain very diverse fans from China, Japan and Korea, among which there are some very rare items, even at the global level, which makes the collections extremely important in Slovenia.

\section{O avtorici}

Nataša Visočnik Gerželj je docentka japonologije na Oddelku za azijske študije, Filozofske fakultete v Ljubljani, kjer tudi poučuje. Doktorirala je na Oddelku za etnologijo in kulturno antropologijo na isti fakulteti, kjer je pred tem zaključila tudi dodiplomski študij skupaj z japonologijo. Njene raziskave so usmerjene na identitetne procese, manjšine, diasporo, marginalnosti in religijo na Japonskem, kjer je tudi izvajala terensko delo. V najnovejši raziskavi pa se ukvarja s korejsko manjšino na Japonskem, predvsem v Kyotu, raziskuje tudi zainichi Korejce, ki so se vrnili v Korejo. V okviru projekta Vzhodnoazijske zbirke $v$ Sloveniji pa se ukvarja s pahljačami, oblačili in nekaterimi vsakodnevnimi predmeti.

\section{About the author}

Nataša Visočnik Gerželj is an Assistant Professor of Japanese Studies at the Department of Asian Studies, Faculty of Arts in Ljubljana, where she also teaches. She received her PhD from the Department of Ethnology and Cultural Anthropology at the same faculty, where she had previously completed her undergraduate studies together with Japanese studies. Her research focuses on identity processes, minorities, diaspora, marginalities, and religion in Japan, where she has also conducted fieldwork. Her latest research deals with the Korean minority in Japan, particularly in Kyoto, but she also investigates zainichi Koreans who have returned to Korea. As part of the East Asian Collections in Slovenia project, she deals with fans, clothing and some everyday objects. 